TABLE V.-Medical Cases: Incidence of Side-effects Following a Total of 803 Injections

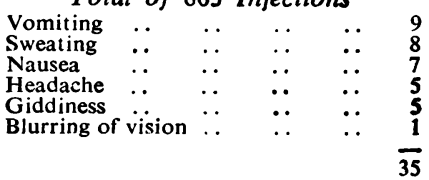

TABLE VI.-Post-operative Cases: Incidence of Side-effects Following a Total of 800 Injections

\begin{tabular}{|c|c|c|c|c|c|c|c|}
\hline & & $\begin{array}{l}\text { Total } \\
\text { Hyster- } \\
\text { ectomy }\end{array}$ & $\begin{array}{l}\text { Pelvic } \\
\text { Floor } \\
\text { Repair }\end{array}$ & $\begin{array}{l}\text { Vaginal } \\
\text { Hyster- } \\
\text { ectomy }\end{array}$ & $\begin{array}{c}\text { Caesar- } \\
\text { ean } \\
\text { Section }\end{array}$ & Others & Total \\
\hline $\begin{array}{l}\text { Sweating } \\
\text { Giddiness } \\
\text { Nausea ... } \\
\text { Vomiting } \\
\text { Headache }\end{array}$ & $\begin{array}{l}\ldots \\
\cdots \\
\cdots \\
\cdots\end{array}$ & $\begin{array}{l}7 \\
2 \\
1 \\
2 \\
1\end{array}$ & $\begin{array}{r}8 \\
2 \\
2 \\
-\end{array}$ & $\begin{array}{l}2 \\
- \\
-\end{array}$ & $\frac{\overline{4}}{2}$ & $\begin{array}{r}4 \\
1 \\
1 \\
-\end{array}$ & $\begin{array}{r}21 \\
10 \\
4 \\
4 \\
1\end{array}$ \\
\hline Total & . & 13 & 12 & 3 & 6 & 6 & 40 \\
\hline
\end{tabular}

veretum ("omnopon") $\frac{1}{3}$ gr. (22 mg.), six-hourly. Adequate post-operative analgesia to facilitate early leg and breathing exercises has been found to be especially valuable, and rigorous adherence to this regimen has lowered the incidence of fatal pulmonary embolism to one in the last 1,000 major gynaecological operations performed by one of us (E. C.).

During this trial no obvious respiratory depression or change in blood pressure or pulse rate occurred, nor did any patient complain of anorexia or constipation. In the dosage used, dipipanone appeared to have little hypnotic effect. The post-operative patients were awake and completely cooperative as soon as the anaesthetic had worn off ; in fact, amylobarbitone sodium, $3 \mathrm{gr}$. $(0.2 \mathrm{~g}$.), had to be given to some of the patients before they were able to go to sleep.

The blood picture of patients whose blood was examined during the trial showed no change attributable to dipipanone. No withdrawal symptoms were noted after up to 80 effective analgesic doses. However, since in the majority of cases pain was short-lived and prolonged analgesia unnecessary, no conclusion can at present be drawn concerning habit formation with this drug.

\section{Morbidity and Mortality}

There were no deaths in the series during the period of the trial. One patient, who had a hysterectomy for fibroids, had a small pulmonary embolism on the fourth day. She was given anticoagulant therapy and made a complete recovery.

\section{Summary}

The results of the administration of a new analgesic, dipipanone hydrochloride, to two distinct series, each of 100 cases, are presented. All the cases treated suffered from pain severe enough to justify the use of a potent analgesic.

In the dosage employed, dipipanone was an effective analgesic. Adequate pain relief was obtained in the great majority of cases of post-operative pain following major gynaecological surgery and of pain due to a variety of acute and chronic medical conditions. Only 3 out of the 200 cases treated failed to obtain any relief from this drug. The optimal dose was found to be $20 \mathrm{mg}$. in the medical cases and $25 \mathrm{mg}$. in the postoperative cases.

The onset of analgesia after subcutaneous injection occurred within 10 minutes and maximal relief was obtained in about 20 minutes in most cases. The effect lasted for approximately five to six hours. There was no obvious depression of respiration or tendency to drowsiness, nor was there any local reaction or pain at the site of injection.
Side-effects were rare, their incidence in relation to the number of doses administered being $4-5 \%$. The only side-effects of any importance were nausea, vomiting, sweating, and giddiness. In only one case were they severe enough to justify transfer to another analgesic.

Our thanks are due to our assistants and to the sisters ir charge of the medical and gynaecological wards at Dudley Road Hospital, Birmingham, without whose co-operation this clinical trial could not have been carried out. The material used in the trial was "pipadone" brand injection of dipipanone hydrochloride, kindly supplied by Burroughs Wellcome and Co.

\section{REFERENCES}

Green, A. F., and Young, P. A. (1951). Brit. J. Pharmacol., 6. 572 Masson, A. H. B. (1956). Anaesthesia, 11, 59.

Ofner, P., Thorp, R. H., and Walton, E. (1949). Nature (Lond.). 163, 479 Walton. E., Green, A. F., and White, A. C. (1950). J. chem. Soc., 3. 2158 .

\section{N-ACETYL-PARA-AMINOPHENOL AS AN ANALGESIC \\ A CONTROLLED CLINICAL TRIAL USING THE METHOD OF SEQUENTIAL} ANALYSIS

BY

D. R. L. NEWTON, M.R.C.P., D.Phys.Med. Assistant, Department of Physical Medicine, St. Thomas's Hospital, London

AND

J. M. TANNER, M.D., Ph.D., D.P.M.

Lecturer, University of London Institute of Child Health, Great Ormond Street, London

Acetanilide and phenacetin have long been used for their analgesic and antipyretic properties. Brodie and Axelrod $(1948,1949)$ have shown that the metabolism in the human body of acetanilide and of phenacetin closely resemble one another in that the major route in each case involves the production of $\mathrm{N}$-acetyl-p-aminophenol (N.A.P.A.P.). In each case a high percentage of the ingested drug is excreted by the kidney as conjugated $\mathrm{N}$-acetyl-p-aminophenol :
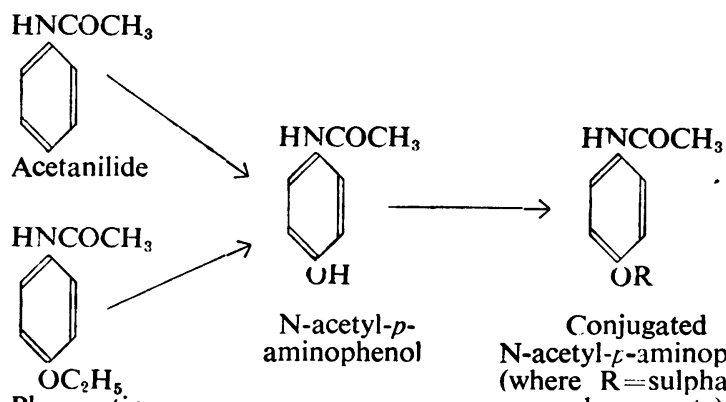

N-acetyl-paminophenol

Conjugated $\mathrm{N}$-acetyl- $x$-aminophenol (where $\mathrm{R}=$ sulphate or glucuronate)

In addition to the major route shown above there is a minor metabolic route which for acetanilide involves the formation of aniline and for phenacetin the formation of $p$-phenetidin. Although neither of these products has been shown to be directly responsible for methaemoglobin formation it is thought that they are both precursors of the methaemoglobin-forming substance. It seems that N.A.P.A.P. is not responsible for 
the formation of methaemoglobin. Neither does it appear to cause the haemolysis occasionally encountered as a toxic manifestation following the administration of acetanilide and phenacetin.

The fact that after ingestion of acetanilide and phenacetin plasma levels of the parent substances remained low whilst the level of N.A.P.A.P. rose rapidly led Brodie and Axelrod to believe that the analgesic and antipyretic properties of both drugs might be due to this derived product. Doses of 1 g. of N.A.P.A.P. given by mouth to human subjects were rapidly absorbed, and peak plasma levels were reached in one to two hours. No methaemoglobin was formed, and it appeared that dose for dose N.A.P.A.P. and acetanilide were equal in analgesic activity.

Using a cutaneous heat-radiation method, Flinn and Brodie (1948) found that the pain threshold of human subjects rose 30 minutes after the ingestion of N.A.P.A.P., reached a peak at two and a half hours, and returned to the baseline at four hours. The maximal rise averaged $30 \%$ as against $4 \%$ for a placebo.

Boreus and Sandberg (1953) found in rats that the analgesic and antipyretic properties of phenacetin and N.A.P.A.P. were approximately equal, though the latter seemed to be less toxic. In human subjects they found that, following a single 3-g. dose of either drug, methaemoglobin formation was low with phenacetin and negligible with N.A.P.A.P.

Batterman and Grossman (1955) carried out controlled trials, using either N.A.P.A.P. or acetylsalicylic acid as an analgesic, and concluded that, with the exception of exudative forms of arthritis, N.A.P.A.P. was a superior analgesic to acetylsalicylic acid alone for the treatment of musculo-skeletal conditions. Side-effects occurred no more commonly than after the administration of a placebo. A dose of N.A.P.A.P. of $3.6 \mathrm{~g}$. daily for up to 116 weeks failed to produce any blood, kidney, or liver disturbances. No uricosuric effect was noted.

Keele (1953) has mentioned N.A.P.A.P. as an analgesic, but so far as we are aware no controlled clinical trial of this drug has been performed in this country, where it is now marketed under the trade name of "panadol."

\section{Purpose of the Trial}

Many patients suffering from musculo-skeletal disorders find that salicylates alone are insufficient to control their symptoms, but a large number gain relief from the use of tab. codein. co. (compound codeine tablets, B.P., containing acetylsalicylic acid 4 gr. $(0.26 \mathrm{~g}$.), phenacetin $4 \mathrm{gr}$. $\left(0.26\right.$ g.), codeine $\frac{1}{8}$ gr. $(8 \mathrm{mg}$.) $)$. However, mild side-effects due to one or other of the constituents commonly occur and sometimes are troublesome enough to preclude the routine use of the drug. Thus if N.A.P.A.P. could be shown to be as effective an analgesic as tab. codein. co., and its side-effects significantly less, it might find a useful place in the treatment of rheumatic disorders, and it was for this reason that a controlled trial of N.A.P.A.P. against tab. codein. co. was carried out.

\section{Selection of Patients}

The patients who took part in the trial were selected by one of us during the course of routine hospital follow-up attendance. They had to conform to the following criteria, which could be rigidly applied since the number of potentially suitable cases was large: (a) The patient was known to require regularly some form of simple analgesic, usually tab. codein. co., to control symptoms. (b) Either by knowledge of the individual patient or the nature of his or her disease the observer could be reasonably certain that the same average level of pain could be expected during the whole four weeks of the trial. (Thus all acute and subacute conditions and those commonly showing frequent periods of pain remission were excluded.) (c) No alteration in therapy by drugs, physical methods, or any other means had been made during the period immediately preceding the trial, and sufficient stability of the patient's condition must have been present to obviate the need for any such change during the trial period of four weeks. (Any alteration in condition during the trial period which necessitated a change in treatment automatically excluded that patient from the trial.)

The cases used in the trial were made up as follows:

Rheumatoid arthritis

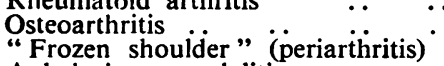

Ankylosing spondylitis

Chronic gout with joint

Cervical spondylosis

\begin{tabular}{|c|c|}
\hline .. & .. \\
\hline . & .. \\
\hline$\cdot$ & $\cdots$ \\
\hline . & $\cdots$ \\
\hline$\ddot{\therefore}$ & . \\
\hline$\ddot{\prime}$ & $\because$ \\
\hline
\end{tabular}

\section{Method of Trial}

The two drugs were compared by their action in the same patient, and each comparison was carried out twice on each patient to ensure greater reliability of result. The statistical technique used in the trial was that known as sequential analysis. Sequential methods appear to have been used in medical research on only one or two occasions in this country, but in many forms of clinical trial they offer great possibilities of economy in material, time, and computation. An excellent introduction to the method was given by Bross (1952) and a more complete account has been published by Armitage (1954).

\section{Administration of Drugs}

The first requirement of a proper clinical trial is to confuse completely the doctor who gives the patient the drugs, and in this we succeeded admirably. The test period for each patient was four weeks. During the first two weeks each patient received drug $A$ for one week and drug $B$ for one week, and at the end of the fortnight was required to say, at his weekly interview with one of us, which, if either, had been more effective in easing his pain. A similar comparison was carried out during weeks three and four. The order in which the drugs were given was randomized, and the doctor was unaware which he was giving. Indeed, at one time he began to believe, despite knowledge of the statistical design, that he could spot which drug was which from the patients' responses. A record was therefore kept for a few weeks, which when later compared with the identification file showed that he scored no better than chance expectation in bis "hunches."

In the first instance each patient was asked to co-operate in the trial of a new analgesic drug: they were never told that they were comparing different drugs, and the few queries which arose were concerned with whether there was a difference in "strength" from one week to the next. At the end of each fortnight the observer questioned the patient concerning his symptoms only: no suggestion was made that different preparations were being compared. The dosage used in the trial was tab. codein. co. 2 three times daily and N.A.P.A.P. 2 tablets (1 g.) thrice daily respectively. Every patient was told to take extra doses of their usual analgesic if required, but it was understood that the trial drug must be the basic medicament.

The randomization was performed as follows: The numbers 1 to 400 were written down in a random order from their appearance in Fisher and Yates tables. Four hundred bottles, stamped 1-400, were then arranged in this order. The first 200 in the row were then filled with drug $A$, and the last 200 with drug $B$, the identification file being made at this point. The first two bottles were taken from the A batch and stamped + , and the first two bottles taken from the $B$ batch and stamped -. These four bottles were tied 
together and constituted the trial drugs for the first patient. The order in which they were given to the patient was: first week, lowest numbered bottle; second week, lowest numbered bottle bearing the opposite sign to that used in the first week; third week, lowest numbered bottle of the two remaining; fourth week, last bottle. The allocation of + and - to pairs of drugs $A$ and $B$ was also randomized-that is, sometimes $A$ was the one with the + and sometimes $B$, so that the signs showed only which two bottles in each batch were of the same substance, without giving a clue to its identity. Needless to say, the appearance of the drugs was made identical by the suppliers.

The possible types of response that the patients could make are listed in Table $\mathrm{I}$.

TABLB I.-Possible Types of Response of Patients in Four-week

\begin{tabular}{c|c|c|c|c}
\multicolumn{4}{|c}{ Trial } \\
\hline \multirow{2}{*}{ Drug } & \multicolumn{4}{|c}{ Response : Preference } \\
\cline { 2 - 5 } & Type 1 & Type 2 & Type 3 & Type 4 \\
\hline A $\}$ & A & A & A & No diff. \\
A $\}$ & A & B & No diff. & " "
\end{tabular}

Type 1 responses include response B,B as well as A,A. Type 2 includes $B, A$ as well as A,B. Type 3 include B. no diff.; no diff.,A; no diff., B as woll as that listed. Only one of the possible orders of giving the drugs has beon exemplified.

Analysis

The practical points about the sequential method as used in the present context can be seen from the Chart, which is Bross's plan B, given at page 198 of his article. The

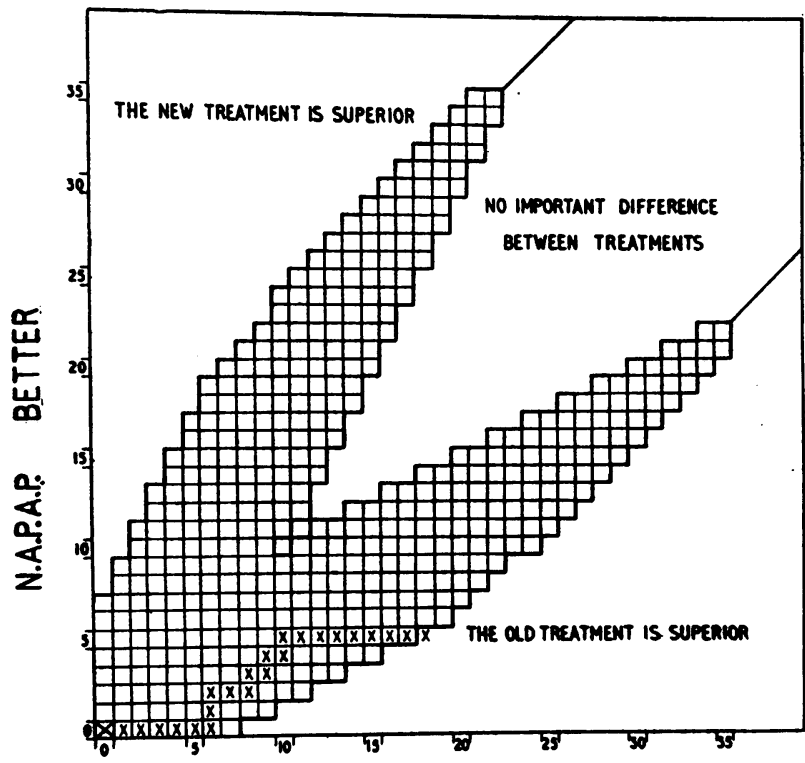

TAB'. CODEIN CO. BETTER

Chart showing result of test, using the method of sequential analysis (Bross, 1952).

principle is this: as each comparison of A and B becomes available, a cross is placed in the square above the lastoccupied one if $A$ is rated superior, or in the square to the right of the last-occupied one if $B$ is rated superior. (If neither is rated superior, no information is obtained and nothing is entered.) The trail of crosses starts at the lower left-hand corner and moves gradually over the plan until sooner or later one of the boundaries is crossed; at this point the experiment is stopped. If the trail goes " north," $A$ is significantly superior; if it goes "east" $B$ is so; if it comes out in the "north-east" sector the conclusion is that so little difference between the treatments exists that there is no point in pursuing the matter further.
The advantages of this type of trial are obvious, especially in the promptness with which the experiment may be stopped immediately an answer is obtained. Different plans, with different boundaries, allow for different levels of significance for the statement "A is superior," and also for different definitions of "no important differences." The present plan uses "A superior to B," with the meaning that if $A$ and $B$ really are equally effective there is only a $5 \%$ chance of our crossing the boundary that designates A as superior. It also draws the boundaries, so that under our conditions anything less than a $10 \%$ advantage of one drug over the other would more likely than not be dismissed as not worth while.

\section{Results}

The present analysis is slightly more complicated than this, owing to the test of $\mathrm{A} v$. B being done twice in each patient. This has two advantages: first, we can make doubly sure that a patient really prefers one drug to the other; second, we can see if one drug particularly suits one patient and the other drug another: in statistical language, we have a test of patient-drug interaction.

In the Chart we have plotted only those preferences which were repeated each time by a patient-that is, the consistent responses listed as type 1 in Table $I$. If an inconsistent response occurred-for example, $A$ was preferred during the first fortnight and $B$ during the next-we ignored it and plotted nothing. The experiment progresses more slowly, but perhaps more surely, this way. The result is seen in the Chart. Eventually, after 42 patients, of whom 23 gave the consistent, type 1 , response and 19 the inconsistent, type 2, 3, or 4, the line of crosses emerged eastwards, indicating that tab. codein. co., the old treatment, was superior to N.A.P.A.P. We can put an actual level of significance on this result if we consider it in a slightly different way (Armitage, personal communication). A more extreme deviation from the null hypothesis than the data we have obtained would result in the boundary being crossed still nearer the origin. There are only five more " extreme" boundary points in this sense than the one our result entered, and the probability of reaching one of these, or the one actually reached, can be calculated as 0.0167 , giving a two-sided significance level of $P=0.033$ to our statement, " tab. codein. co. is superior to N.A.P.A.P." A similar result was achieved when each fortnightly comparison was plotted, irrespective of whether the patient was consistent from one fortnight to the next.

The interesting question remains whether a particular group of patients does better on one drug, while another group does better on the other.

The testing of interaction in sequential analysis is still somewhat uncertain, but a test can be easily made of our total results, ignoring for the present the sequential design. The preferences were: tab. codein. co. twice, 18 ; N.A.P.A.P. twice, 5 ; mixed, 8 (the remainder having " no preference " on their cards). A $\chi^{2}$ test can be applied to see if a greater proportion falls into the "twice" categories than would be expected on the basis of the total preferences made. The numbers in each category expected by chance can be simply enumerated: tab. codein. co. scored a total of $71 \%$ of all preferences and N.A.P.A.P. $29 \%$, so that the proportions expected purely by chance combinations are $0.71^{2}, 2 \times 0.71 \times 0.29$, and $0.29^{2}$ for the categories tab. codein. co. twice, mixed, and N.A.P.A.P. twice.

The details are displayed in Table II, where the excess of consistent over inconsistent responses is clearly seen.

TABLE II.-Test of Patient-Drug Interaction

\begin{tabular}{|c|c|c|c|c|}
\hline $\begin{array}{l}\text { Type of } \\
\text { Preference }\end{array}$ & & Expected & Observed & $\begin{array}{c}\text { Difference } \\
\text { (Observed-Expected) }\end{array}$ \\
\hline $\begin{array}{l}\text { Tab. codein. co. twice } \\
\text { Mixed } \\
\text { N.A.P.A.P. twice } \quad \cdots\end{array}$ & $\begin{array}{l}\ldots \\
\cdots \\
\cdots\end{array}$ & $\begin{array}{r}31 \\
26 \\
5\end{array}$ & $\begin{array}{l}36 \\
16 \\
10\end{array}$ & $\begin{array}{r}+5 \\
-10 \\
+5\end{array}$ \\
\hline
\end{tabular}

$x^{2}=9 \cdot 6$, df $2, P<0.01$ 
$\chi^{2}$ comes to 9.6 for 2 degrees of freedom, which corresponds to a probability of under $1 \%$. There is good evidence, therefore, that patient-drug interaction exists in this experiment-that is, that though in general tab. codein. co. is the better drug, for some people N.A.P.A.P. is consistently superior.

\section{Discussion}

We have thus reached the conclusion that, under the conditions of this experiment, tab. codein. co. in a dosage of two tablets three times a day is for most patients a significantly better analgesic than N.A.P.A.P. in a dosage of $1 \mathrm{~g}$. three times a day. This ignores possible differences in side-reactions, which were inquired for every week. Only three patients complained of consistent side-effects-that is, during both weeks that the same drug was being taken. The complaint was of malaise in one and nausea in the other two, and occurred with tab. codein. co. Apart from these three cases the number of inconsistent side-effects was slightiy greater during the administration of tab. codein. co. than with N.A.P.A.P. and consisted mainly of constipation, nausea, and giddiness, but no statistical significance between the two drugs in this respect could be demonstrated.

A significant minority of patients judged consistently that for them N.A.P.A.P. was the better drug. It is just possible that despite appearances some of these patients were able to detect a difference in some aspect of the tablets; if so, then the consistency of the second response might be spurious, suggestion being carried over from their first preference to sway their judgment on the second trial. But if we discount this possibility, as we think we may, it seems we have proof of the individual reaction to different types of analgesic.

Some patients took additional analgesics, mostly acetylsalicylic acid or tab. codein. co., during the whole or part of the trial period, but we can find no evidence that this tended to produce a preference for one drug rather than the other, or to produce consistency in preference rather than inconsistency. There was no evidence of preference for one or the other drug amongst patients belonging to any particular diagnosis group.

Lastly, a word should be said about the use of sequential analysis in a trial of this sort. We found this technique very useful and readily communicable to physicians without statistical sophistication: we hope this experiment will further its introduction into clinical trials, and direct attention also to the possibilities and desirability of including in the statistical design a test of patient-drug interaction, or patients' personal suitability for a particular drug.

\section{Summary}

N-acetyl-p-aminophenol (N.A.P.A.P.) is the non-toxic metabolite of acetanilide and phenacetin through which those drugs appear to exert their antipyretic and analgesic action in the human body, and has recently come on to the British market under the trade name of "panadol."

A controlled clinical trial of the analgesic effect of N.A.P.A.P. compared with that of tab. codein. co. B.P. has been carried out in patients suffering from chronic painful rheumatic conditions. Every patient received one drug for a period of a week followed by the other during a second week, and at the end of the fortnight was required to state which drug was the more effective. During the following fortnight a second similar comparison was made. The drugs were given under a randomization scheme which ensured that at no time did either the patient or the doctor know which drug was being taken.

The statistical method known as sequential analysis was used, the principles and advantages of which are described. In the main analysis only patients whose preferences were consistent from one fortnight to the next were plotted. After 42 patients had been tested the analysis terminated with the result that tab. codein. co. 2 tablets three times a day was in general superior to N.A.P.A.P., 1 g. (2 tablets) three times a day. No significant side-effects were noted during the administration of N.A.P.A.P.

The repetition of the test in each patient makes it possible to assess patient-drug interaction-that is, whether there is a significant tendency for particular patients to prefer N.A.P.A.P. even though the majority prefer tab. codein. co. A $\chi^{2}$ test between the numbers whose preferences were consistent and those who were inconsistent shows that this tendency does in fact exist.

Thus the design of the experiment permits us to state: (1) that tab. codein. co. is a superior analgesic to N.A.P.A.P. in the majority of patients of the sort we tested ; and (2) that nevertheless a significant minority of individuals judge that for them N.A.P.A.P. is a better analgesic.

We wish to thank Bayer Products Ltd., who supplied the drugs; Dr. P. Bauwens for his advice and for permission to carry out the trial; Dr. R. P. Hickey for his assistance; and Dr. R. S. Stacey and Dr. P. Armitage for their criticism and advice during the preparation of this paper.

\section{REFERENCES}

Armitage, P. (1954). Quart. J. Med., 23, 255.

Batterman, R. C., and Grossman, A. J. (1955). Fed. Proc., 14, 316 Boreus, L.-O., and Sandberg. F. (1953). Acta physiol. scand., 28, 261 Brodie, B. B.. and Axelrod. J. (1948). J. Pharmacol., 94, 29.

Bross, I. (1952). Biometrics, 8. 188.

Flinn, F. B., and Brodie. B. B. (1948). J. Pharmacol., 94, 76.

Keele, C. A. (1953). Practitioner, 170, 516.

\section{BARBITURATE POISONING TREATED WITH AMIPHENAZOLE AND BEMEGRIDE}

BY

\author{
ARNOLD WORLOCK, M.B., B.S. \\ Darlington Memorial Hospital
}

Amiphenazole ("daptazole"; 2:4-diamino-5-phenylthiazole hydrochloride) and bemegride (" megimide"; $\beta$-ethyl- $\beta$-methylglutarimide) were introduced as a result of work by Shaw and Shulman (1955) and Shulman et al. (1955). Twelve cases of fairly severe barbiturate intoxication, in which all the patients were unconscious on admission, treated with these two drugs are recorded below.

\section{Method}

All the patients were first seen in the casualty department and adnitted to the medical wards, where their condition was assessed and a full examination made, particular attention being paid to the depth of coma. This was followed by a stomach wash-out with a solution of dilute sodium bicarbonate, $4 \mathrm{oz}$. $(114 \mathrm{ml}$.) of this solution remaining in the stomach after the wash-out had been completed. The airway was kept clear, using suction or intubation as necessary; and in all cases a laryngoscope was passed to determine whether laryngeal reflexes were present. A $5 \%$ glucosesaline intravenous drip was set up and continued running at a rate of 40 drops a minute throughout the treatmentthat is, until the patient recovered consciousness. All patients were given 600,000 units of procaine penicillin at once and then twice daily for five days. Amiphenazole and bemegride were injected intravenously at a rate of $1 \mathrm{ml}$. of amiphenazole and $10 \mathrm{ml}$. of bemegride every three minutes until a level of light anaesthesia was attained. The strengths 